\title{
Impact of Seminal Plasma Zinc and Serum Zinc Level on Semen Parameter of Fertile and Infertile Males
}

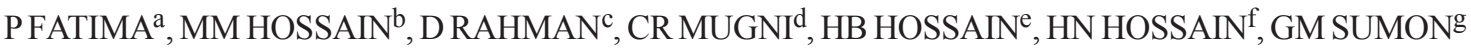

\begin{abstract}
Summary:
Background: Despite Zinc (Zn) deficiency being prevalent in humans, less emphasis has been given on the understanding of its impact on male reproduction. Spermatogenesis has a strict requirement for zinc. The relationship of seminal plasma zinc level and semen parameter until now is controversial.
\end{abstract}

Objective : The study was done to find out the impact of seminal plasma zinc and serum zinc level on semen parameter of fertile and infertile males.

Subjects and methods: The study was done in Center for Assisted Reproduction, a tertiary Infertility center in Dhaka and in the Biochemistry Department of Bangabandhu Sheik Mujib Medical University (BSMMU), Dhaka. Sixteen fertile males were taken as control and sixty nine infertile males were taken as cases. Semen analysis was done according to WHO criteria (.2004). Serum zinc and seminal plasma zinc levels were measured in the Biochemistry Department of BSMMU by Graphite Furnace Atomic Absorption Spectrophotometer.

Result: Seminal parameters between fertile and infertile men showed significantly high sperm count, sperm motility, rapid linear motility, and morphology in fertile group. In fertile men, serum zinc level was lower than the infertile

Introduction:

Zinc is essential for reproduction in human. World Health Organization (WHO) estimates that one-third of world population is deficient in zinc. The geographical regions

a. Prof. Parveen Fatima, Professor (Infertility), BSMMU

b. Prof. Mohammad Moazzam Hossain, Professor \& Chief Embryologist, Centre for Assisted Reproduction

c. Dr. Dilruba Rahman, Co-ordinator IVF, Centre for Assisted Reproduction

d. Dr.Chowdhury Rashedul Mugni, EMO, BIRDEM

e. Dr. Humayra Bushra Hossain, Medical Officer, Centre for Assisted Reproduction

f. Dr. Humayra Nawrin Hossain, Medical Officer, Centre for Assisted Reproduction,

g. Dr. G.M. Sumon, Asst. Director, Hospital, Centre for Assisted Reproduction

Address of Correspondence: Prof. Parveen Fatima, Professor of Infertility, Centre for Assisted Reproduction, 2/1-A, Iqbal Road, Mohammadpur, Dhaka-1207, Bangladesh. e-mail : drpfatima@gmail.com group, whereas the seminal plasma zinc level was higher in the fertile than the infertile group which was not statistically significant. In fertile men except for serum zinc, all parameters showed positive relationship; and in infertile men, except sperm morphology, all other parameters showed negative relationship. Seminal plasma zinc shows positive correlation with all semen parameters in fertile group and negative correlation in infertile group except for sperm morphology. There is negative correlation of serum zinc and seminal zinc-in both groups. Regarding other parameters, semen zinc shows positive correlation with all parameter except sperm morphology in fertile men and negative correlation with all parameter except sperm count in infertile men.

Conclusion: Seminal zinc levels in fertile men are higher than those in the infertile patients although the serum zinc level is lower. Zinc levels in seminal plasma has a direct relationship with semen parameters. Zinc deficiency may be an important risk factor for low semen parameters and idiopathic male infertility.

Key words: Seminal plasma zinc, Semen parameter, Male infertility.

(J Bangladesh Coll Phys Surg 2017; 35: 15-19)

most affected are believed to be in descending order of severity, South Asia (in particular, Bangladesh and India), Africa and the Western Pacific ${ }^{1}$. Although there is high prevalence of zinc deficiency in humans, the consequences of zinc deficiency on male reproduction is not well-understood. The Zinc concentration of semen is 87 times than that in the blood and has been reported to protect sperm from bacteria and chromosomes damage ${ }^{2}$. Male fertility is influenced by zinc and plays an important role in normal testicular development, spermatogenesis, and sperm motility ${ }^{3,4}$. The concentration of zinc in human seminal plasma is higher than in other tissues. There are conflicting reports on the role of human seminal plasma zinc on sperm quality. Some authors reported significantly different seminal zinc levels between fertile and subfertile groups, indicating low seminal zinc levels in the subfertile populations, ${ }^{5,6}$ while some others have shown that there is no difference between the two groups ${ }^{7,8}$. Low zinc 
levels have a negative effect on serum testosterone concentration and seminal volume ${ }^{9}$. Infertile males have lower levels of seminal plasma zinc, which is associated with reduced levels of zinc in the blood ${ }^{9}$. Zinc in seminal plasma stabilizes the cell membrane and nuclear chromatin of spermatozoa ${ }^{10,11}$. It may also have an antibacterial function ${ }^{12}$ and protect the testes against the degenerative changes ${ }^{13}$. It may play a regulatory role in the process of capacitation and acrosome reaction ${ }^{14}$. Despite the high prevalence of marginal $\mathrm{Zn}$ deficiency in humans, less emphasis has been placed on the understanding of its impact on male reproduction. Poor zinc nutrition may be an important risk factor for low quality of sperm and idiopathic male infertility ${ }^{15}$. The study was done to find the impact of seminal plasma zinc and serum zinc levels on semen parameters in fertile and infertile males.

\section{Materials and methods:}

The study was done in Center for Assisted Reproduction, a Tertiary infertility center in Dhaka, and in the Biochemistry Department of Bangabandhu Sheikh Mujib Medical University, Dhaka. Sixteen fertile males whose wives were pregnant at the time of the assessment were taken as control and sixty nine infertile males whose wives were facing difficulty in conceiving due to poor semen parameters, were taken as cases. Semen analysis was done according to as per World Health Organization guidelines (2004). Serum zinc and seminal plasma zinc levels were measured in the Biochemistry Department of BSMMU by Graphite Furnace Atomic Absorption Spectrophotometer.

\section{Results:}

In Table I semen parameters and zinc levels of the fertile and infertile males showed mean semen volume to be $2.46 \pm 1.27 \mathrm{ml}$ and $2.47 \pm 1.07 \mathrm{ml}$ respectively which was statistically not significant. Comparison of other seminal parameters between fertile and infertile group showed significantly positive parameters in fertile group. Total sperm count, total sperm motility, rapid linear motility of sperm and sperm morphology were $85.00 \pm 32.04$ and $47.87 \pm 46.45$ million $/ \mathrm{ml}(\mathrm{P}<0.01)$; $81.88 \pm 7.50$ and $52.39 \pm 23.68 \%(\mathrm{P}<0.001) ; 69.06 \pm 8.98$ and $31.45 \pm 20.55 \%(\mathrm{P}<0.001)$; and $52.50 \pm 4.47$ and $25.00 \pm 11.97 \%(\mathrm{P}<0.001)$ respectively among the fertile(control) and infertile(case) group. Comparison of serum zinc and semen zinc between control and case showed no significant difference in serum zinc $68.39 \pm 14.37$ and $75.83 \pm 17.41 \mathrm{ig} / \mathrm{dl}(\mathrm{P}=0.116)$; and semen plasma zinc 6,175.44 $\pm 2,569.52$ and 5,851.46 $\pm 2,076.11 \mathrm{ig} /$ $\mathrm{dl}(\mathrm{P}=0.593)$ respectively.

Table II shows correlation coefficient (r) of seminal plasma zinc concentration with semen parameters. In fertile group, all parameters showed positive relationship; and in infertile, except sperm morphology, all other parameters showed negative relationship. In fertile group, only semen motility showed statistically significant relationship $(\mathrm{r}=+0.504, \mathrm{P}<0.05)$; but none in infertile group.

Table III shows correlation coefficient ( $\mathrm{r}$ ) of serum zinc concentration with semen parameters. In control, except semen morphology and semen zinc, all parameters

Table-I

Semen parameters and Zinc levels in fertile and infertile males

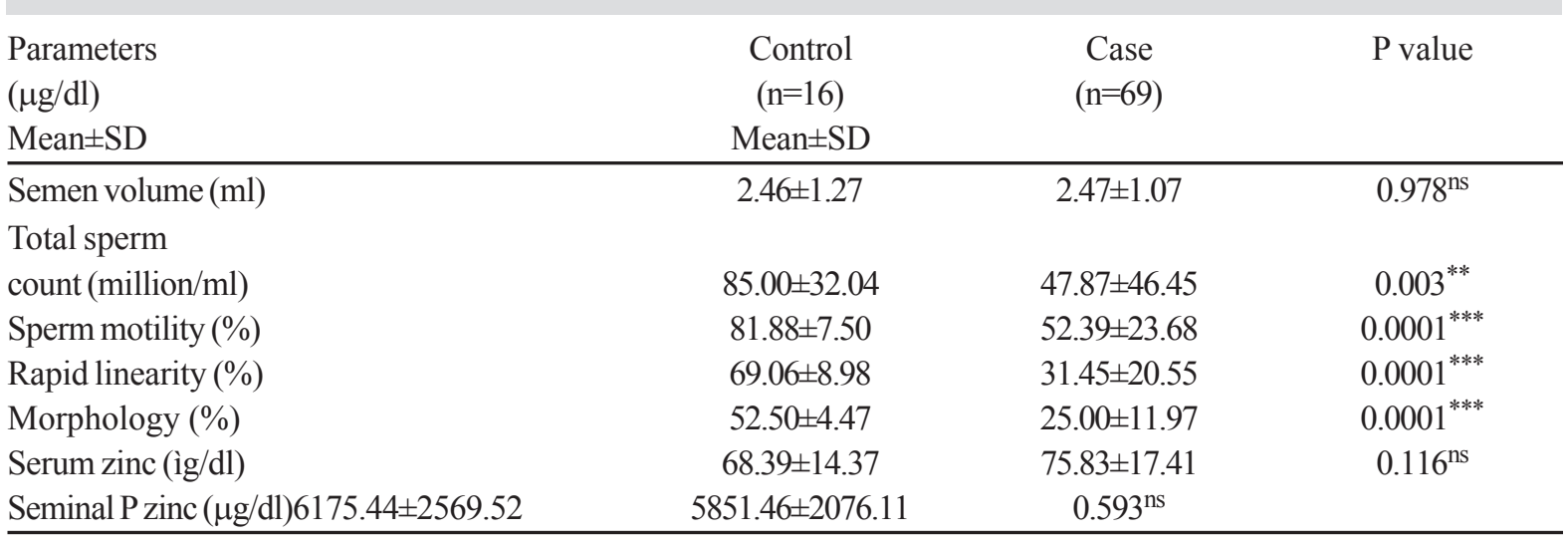

Unpaired Student's 't' test, $\mathrm{ns}=$ Not significant, $* *=$ Significant $(\mathrm{P}<0.01), * * *=$ Significant $(\mathrm{P}<0.001)$ 
Table-II

Correlation coefficient (r) of seminal plasma zinc concentration with semen parameters

\begin{tabular}{lcccc} 
fertile $(\mathrm{n}=16)$ & \multicolumn{4}{c}{ infertile $(\mathrm{n}=69)$} \\
\cline { 2 - 5 } Parameters & r value & P value & r value & P value \\
\hline Volume $(\mathrm{ml})$ & +0.384 & $0.142^{\mathrm{ns}}$ & 0.164 & $0.179^{\mathrm{ns}}$ \\
Total sperm count & +0.080 & $0.768^{\mathrm{ns}}$ & 0.222 & $0.067^{\mathrm{ns}}$ \\
(million/ml) & & & \\
Motility $(\%)$ & +0.504 & $0.047^{*}$ & 0.076 & $0.536^{\mathrm{ns}}$ \\
Rapid linearity $(\%)$ & +0.426 & $0.100^{\mathrm{ns}}$ & 0.048 & $0.698^{\mathrm{ns}}$ \\
Morphology $(\%)$ & +0.298 & $0.262^{\mathrm{ns}}$ & +0.156 & $0.202^{\mathrm{ns}}$ \\
\hline
\end{tabular}

Pearson correlation coefficient test, $\mathrm{ns}=$ Not significant, $*=$ Significant $(\mathrm{P}<0.05)$

Table-III

Correlation coefficient (r) of serum zinc concentration with semen parameters

\begin{tabular}{lcccc} 
Control $(\mathrm{n}=16)$ & \multicolumn{4}{c}{ Case $(\mathrm{n}=69)$} \\
\cline { 2 - 5 } Parameters & r value & P value & r value & P value \\
\hline Volume $(\mathrm{ml})$ & +0.130 & $0.631^{\mathrm{ns}}$ & 0.086 & $0.481^{\mathrm{ns}}$ \\
Total sperm count & +0.079 & $0.770^{\mathrm{ns}}$ & +0.086 & $0.481^{\mathrm{ns}}$ \\
(million/ml) & & & $0.988^{\mathrm{ns}}$ \\
Motility $(\%)$ & +0.337 & $0.201^{\mathrm{ns}}$ & 0.002 & $0.595^{\mathrm{ns}}$ \\
Rapid linearity $(\%)$ & +0.508 & $0.045^{*}$ & 0.065 & $0.069^{\mathrm{ns}}$ \\
Morphology $(\%)$ & 0.368 & $0.161^{\mathrm{ns}}$ & 0.220 & $0.360^{\mathrm{ns}}$ \\
Semen zinc $(\mathrm{ig} / \mathrm{dl})$ & 0.019 & $0.945^{\mathrm{ns}}$ & 0.112 & \\
\hline
\end{tabular}

Pearson correlation coefficient test, $\mathrm{ns}=$ Not significant, $*=$ Significant $(\mathrm{P}<0.05)$

showed positive relationship; and in case, except semen total sperm count, all other parameters showed negative relationship. In control, only semen rapid linearity showed statistically significant relationship $(\mathrm{r}=+0.508$, $\mathrm{P}<0.05$ ); none of the parameters showed significant relationship in case group.

\section{Discussion:}

About 6 decades ago, zinc was recognized as an essential micronutrient for human health by Dr. Ananda Prasad, a nutrition chemist at Wayne State University in Detroit, Michigan ${ }^{16}$. The human body contains approximately $2 \mathrm{~g}$ zinc in total. Daily requirement of zinc is $10 \mathrm{mg} \mathrm{Zn}$ per day for adult women and $12 \mathrm{mg} \mathrm{Zn} \mathrm{per}$ day for adult men. World Health Organization estimates that zinc deficiency affects one-third of the world's population (about two billion people) with the prevalence rates ranging from 4 to $73 \%$ in various regions ${ }^{17}$. In 1990 lower levels of zinc were noticed in infertile patient by Kvist et al ${ }^{18}$ which was similar in our study.

Some studies indicated that there is no significant difference between Zinc content in fertile and infertile men ${ }^{19-22}$.Although in our study serum zinc and seminal zinc was low between fertile and infertile group also did not show any significant difference, serum zinc $68.39 \pm 14.37$ and $75.83 \pm 17.41 \mathrm{ig} / \mathrm{dl}(\mathrm{P}=0.116)$; and semen zinc $6,175.44 \pm 2,569.52$ and 5,851.46 $\pm 2,076.11 \mathrm{ig} / \mathrm{dl}$ $(\mathrm{P}=0.593)$, but some studies found a significant difference between them ${ }^{23-26}$. In our study,fertile subjects had higher levels of zinc in their seminal plasma than infertile group which was in concurrence with the study of Colagar ${ }^{15}$.

Comparison of other seminal parameters between fertile and infertile group showed significantly positive parameters in fertile group with statistically significant 
increase in total sperm count, total sperm motility, rapid linear motility of sperm and sperm morphology among the fertile(control) and infertile(case) group. Similar findings have reported in previous studies by different authors. High concentration of zinc to be associated with enhanced sperm parameters, including sperm count, motility $23-25,27$, and normal morphology 25,28 , Zhao et $\mathrm{al}^{26}$ observed a positive relationship between poor production of sperm and poor sperm motility with a lower content of $\mathrm{Zn}$ in the seminal plasma of infertile subjects which is in concurrence with our study. In a study done in 1983 Stanwell found a significant positive relationship between sperm density and seminal plasma zinc concentration in the fertile, but not in the infertile men ${ }^{29}$. Wong et al. ${ }^{19}$ reported increased proportion of spermatozoa with progressive motility after oral zinc supplementation. Steven et al. ${ }^{30}$ in his study observed a negative correlation between seminal zinc content and sperm head defect. In the present study it was observed that there is positive but not significant correlations between zinc content of seminal plasma and motility, total count and sperm concentration. In contrast to our study Wong et al. ${ }^{4}$, demonstrated that zinc content in fertile men were not different from those of infertile men. Abou-Shakra et al. ${ }^{31}$, reported that zinc content in men grouped by sperm concentration was not different from each other.

\section{Conclusion:}

Zinc may contribute to fertility through its significant effects on various semen parameters. It seems that the estimation of seminal plasma zinc may help in investigation and treatment of infertile males. Seminal zinc may contribute to fertility through its effect on various semen parameters. Seminal zinc level in fertile men is higher than the infertile patients although the serum zinc level is lower. Zinc levels in seminal plasma has a direct relationship with semen parameters. Zinc deficiency may be an important risk factor for low quality of sperm and idiopathic male infertility.

\section{Reference:}

1. Holt $\mathrm{C}$, Brown $\mathrm{KH}$, eds. International Zinc Nutrition Consultative Group (IZiNCG) Technical Document \#1. Assessment of the risk of zinc deficiency in populations and options for its control. Food and Nutrition Bulletin, 2004, 25 (Suppl 2):S94-S203.

2. Judith EB. Nutrition through life cycle. 3rd ed. St. Paul, Minnesota: Brooks/Cole publishing company; 2008.
3. Lin TH, Cheng SY. Determination of zinc fractions in human blood and seminal plasma by ultrafiltration and atomic absorption spectrophotometry. Biol Trace Elem Res, 1996; 51(3): 267-276.

4. Wong WY, Flik G, Groenen PM, Swinkels DW, Thomas $\mathrm{CM}$, Copius-Peereboom JH, et al. The impact of calcium, magnesium, zinc, and copper in blood and seminal plasma on se-men parameters in men. Reprod Toxicol 2001; 15(2): 131-136.

5. Chia SE, Ong CN, Chua LH, et al. Comparison of zinc concentrations in blood and seminal plasma and the various sperm parameters between fertile and infertile men. J Androl. 2000;21:53-7.

6. Ebisch MW, Pierik FH, Jong FH, Thomas CM, Theunissen RP. Does folic acid and zinc sulphate intervention affect endocrine parameters and sperm characteristics in men. Int J Androl. 2006;29:339-45.

7. Umeyama T, Ishikawa H, Takeshima H, Yoshii S, Koiso $\mathrm{K}$. A comparative study of seminal trace elements in fertile and infertile men. Fertil Steril. 1986;46:494-9. [PubMed]

8. Omu EA, Fernandes S. The relationship between zinc/ cadmium ratio in human semen: Effect on immune response. Kuwait Med J. 2001;33:38-43.

9. Hunt CD, Johnson PE, Herbel J, Mullen LK. Effects of dietary zinc depletion on seminal volume and zinc loss, serum testosterone concentrations, and sperm morphology in young men. Am J Clin Nutr. 1992;56: 148-57.

10. Chvapil M. New aspects in biological role of zinc. A stabilizer of macromolecules and biological membrane. Life Sci 1973;13:1041-9.

11. Kvist U. Sperm nuclear chromatin decondensation ability. An in vitro study on ejaculated human spermatozoa. Acta physiol scand suppl 1980;486:1-24

12. Langley J, Goldsmid J, Davies N. Venereal trichomoniasis role in men. Genitourin Med 1987;63:264-7.

13. Batra N, Nehru B, Bansal MP. Reproductive potential of male Portan rats exposed to various levels of lead with regard to zinc status. Br J Nutr 2004;91:387-91.

14. Riffo M, Leiva S, Astudillo J. Effect of zinc on human sperm motility and acrosome reaction. Int J Androl 1992;15:229-37.

15. Colagar AH, Marzony ET, Chaichi MJ. Zinc levels in seminal plasma are associated with sperm quality in fertile and infertile men. Nutrition Research, 2009; 29(2): 82-88.

16. Prasad AS. Clinical, endocrinological and biochemical effects of zinc deficiency. Clinics in Endocrinology and Metabolism 1085;14: 567-585

17. World Health Organization. The World Health Report 2002: reducing risks, promoting healthy life. Geneva: WHO, 2002. 
18. Kvist, U, Kjellberg, S, Bjorndahl L, Soufir JC, Arver S. Seminal fluid from men with agenesis of the Wolffian ducts zinc binding properties and effects on sperm chromatin stability. InL J Androl 1990; 13: 245-252

19. Wong WY, Thomas CM, Merkus JM, Zielhuis GA, Steegers-Theunissen RP Male factor sub-fertility: possible causes and the impact of nutritional factors. Fertil Steril 2000; 73(3): 435-442.

20. Bakalczuk S, Robak-Cholubek D, Jakiel G, Krasucki W. Level of zincand magnesium in semen taken from male partners of married infertilecouples. Ginekol Pol 1994;65:67-70.

21. Colleen S, Mardh PA, Schytz A. Magnesium and zinc in seminal fluid of healthy males and patients with nonacute prostatitis with and without gonorrhoea. Scand J Urol Nephrol 1975;9:192-7.

22. Carpino A, Siciliano L, Petroni MF, De Stefano C, Aquila $\mathrm{S}$, Ando S,et al. Low seminal zin bound to high molecular weight proteins in asthenozoospermic patients: evidence of increased sperm zinc content in oligoasthenozoospermic patients. Hum Reprod 1998;13:111-4.

23. Fuse H, Kazama T, Ohta S, Fujiuchi Y. Relationship between Zinc concentrations in seminal plasma and various sperm parameters. Int Urol Nephrol 199 9;31:401-8.

24. Mankad M, Sathawara NG, Doshi H, Saiyed HN, Kumar S. Seminal plasma zinc concentration and á-glucosidase activity with respect to semen quality. Biol Trace Elem Res 2006;110:97-106

25. Chia SE, Ong C, Chua L, Ho L, Tay S. Comparison of zinc concentration in blood and seminal plasma and various sperm parameters between fertile and infertile men. J Androl 2000;21:53-7.

26. Zhao RP, Xiong CL. Zinc content analysis in serum, seminal plasmaand spermatozoa of asthenozoospermic and oligoasthenozoospermic patients. Zhonghua Nan Ke Xue 2005;11:680-2

27. Caldamone AA, Freytag MK, Cockett AT. Seminal zinc and maleinfertility. Urology 1979;13:280-1

28. Edorh AP, Tachev K, HadouT, Gbeassor M, Sanni A, Creppy EE, et al.Magnesium content in seminal fluid as an indicator of chronic prostatitis. Cell Mol Biol 2003;49:419-23.

29. Stanwell-Smith R, Thompson SG, Haines AP, Ward RJ, Cashmore G, Stedronska J, et al. A comparative study of zinc, copper, cadmium, and lead levels in fertile and infertile men. Fertil Steril 1983; 40(5): 670-677.

30. Steven FS, Griffin MM, Chantler EN Inhibition of human and bovine sperm acrosin by divalent metal ions. Possible role of zinc as a regulator of acrosin activity. Int $J$ Androl 1982; 5(4) : 401-412.

31. Abou-Shakra FR, Ward NI, Everard DM. The role of trace elements in male infertility. Fertil Steril 1989; 52(2): 307-310 